\title{
Assessment of dehydration, sweat rate, electrolyte loss through the field sweat test on athletes
}

\author{
Sujin Bae \& Park Hyon* \\ Exercise Nutrition \& Biochemistry Lab. Kyung Hee University
}

\begin{abstract}
[Purpose] The purpose of this study was to confirm and evaluate the assessment of dehydration, whole body sweat rate, sweat sodium potassium concentration, and fluid intake during workout in college badminton and rugby athletes using the field sweat test. [Methods] 14 male badminton athletes and 17 male rugby athletes were measured during an usual training session in a typical environment. USG(urine specific gravity) was measured before the start of training. Whole body sweat rate, sweat sodium·potassium concentration, and fluid intake were measured during and post a session of training. [Results] USG higher than 1.023 in both groups, which was considered as dehydrated. Sweating rate were $1.037 \pm 0.315 \mathrm{~L} / \mathrm{h}$ for the badminton athletes and $1.987 \pm 0.386 \mathrm{~L} / \mathrm{h}$ for the rugby athletes. The concentration of sodium and potassium were $53.6 \pm 20.2 \mathrm{mmol} / \mathrm{L}, 4.1 \pm 0.7 \mathrm{mmol} / \mathrm{L}$ for badminton athletes, and $55.6 \pm 15.2 \mathrm{mmol} / \mathrm{L}, 4.3 \pm 0.5 \mathrm{mmol} / \mathrm{L}$ for rugby athletes, respectively. The loss of sodium and potassium were $1.02 \pm 0.48 \mathrm{~g}, 0.08 \pm 0.02 \mathrm{~g}$ for badminton athletes, and $1.95 \pm 0.52 \mathrm{~g}, 0.15 \pm 0.03 \mathrm{~g}$ for rugby athletes, respectively. [Conclusion] In this study, a standard protocol of field sweat test was suggested as a useful factor in evaluating athletes' hydration status and electrolyte loss during a routine in-door or out-door training session. And, it is expected to build reliable data to establish a standard hydration guideline for Korean athletes.
\end{abstract}

Key words: Hydration assessment, Sweat test, USG(urine specific gravity), Sweat rate, Sweat sodium $\cdot$ potassium concentration, Dehydration

\section{서 론}

체수분 상태평가(hydration assessment)와 발한테스 트(sweat test)는 운동선수나 일반인의 체수분 상태를 평가하고, 땀의 배출로 인한 탈수(dehydration) 및 전해 질 상태를 분석하는 가장 보편적이고 표준화된 방법이다 (Kilding et al., 2009, Shirreffs \& Sawka, 2011, Baker, 2016). 운동 전 체수분 상태는 주로 요비중 (urine

논문 투고일 : 2020. 03. 16.

논문 수정일 : 2020. 05. 01.

게재 확정일 : 2020. 05. 14.

* 교신저자 : 박 현(hpark@khu.ac.kr). specific gravity: USG)으로 평가하며(Cheuvront \& Sawka, 2005), 운동 중 체수분 손실 량은 체중 변화 차 이를 계산하여 평가한다(Shirreffs, 2003). 땀의 전해질 분석은 전신 전해질 손실량을 파악하기 위해 필수적으로 측정해야 하는 항목이며, 스포츠 현장에서 이를 분석하기 위해 땀을 수집할 때는 땀 흡수 패치를, 전해질 농도는 휴 대용 전해질 분석기를 주로 활용한다(Baker et al., 2009, Baker et al., 2014).

고교, 대학, 프로 운동선수들의 운동 전 체수분 상태와 운동 중 발한율(sweat rate)을 토대로 수분 섭취 지침을 제안한 McDermott et al.(2017)의 연구에서는 약 50\% 
이상의 운동선수들이 수분이 부족한 상태로 훈련 및 시합 에 임한다고 보고하였다. NBA(National Basketball Association)에 소속된 선수들을 대상으로 진행한 수분 섭취 실태 조사에서는 $52 \%$ 의 선수가 정상 범위보다 낮은 수분 상태로 경기에 임했으며, 경기 중 수분 섭취량은 발 한량(sweat loss)보다 훨씬 적었다(Osterberg et al., 2009). 유소년 농구, 체조, 수영, 육상, 카누 선수들을 대 상으로 진행한 수분 섭취 실태 조사 연구에서도 $74.5 \%$ 가 낮은 수분 상태로 경기에 임했다(Arnaoutis et al., 2015).

운동 중 체중의 $2 \%$ 에 해당하는 수분이 손실되면 운동 능력은 약 $10 \%$ 내외까지 감소한다(Bradley et al., 2015). 지구성 운동의 경우, 체중의 $3 \%$ 이상 탈수가 일 어날 시 운동능력의 감소가 현저히 일어난다(Goulet, 2013). 숙련된 육상선수의 $5,000 \mathrm{~m}, 10,000 \mathrm{~m}$ 경주에서 체중의 1.6 2.1\% 탈수가 일어났을 때 유의하게 느려졌 다(Armstrong et al., 1985). 그리고 65\% VO2peak 강 도로 90 분 동안 싸이클을 진행한 후에 타임 트라이얼을 통해 기록을 측정한 연구에서 수분 비섭취군은 $3.1 \%$ 탈 수가 일어났고 수분 섭취군에 비해 $13 \%$ 느렸다(LoganSprenger et al., 2015). 무산소성 운동의 경우, 종목별 로 무산소성 대사과정이 달라 어느 정도의 탈수 수준이 운동능력에 영향을 주는지 명확히 표현하기는 어렵지만, 체중의 약 $2 \%$ 탈수가 일어났을 때 운동능력이 감소하며, 체중의 약 3 4\% 탈수가 진행되면 운동능력의 추가적인 감소가 나타났다(Kraft et al., 2012). 체중의 1.5\% 탈 수에서 벤치프레스 측정 시 $1 \mathrm{RM}$ 중량은 약 $6.6 \%$ 감소하 였고(Schoffstall et al., 2001), 최대 12회 반복할 수 있 는 중량으로 각 부위별 웨이트 운동을 했을 때, 체중의 $3 \%$ 탈수에서 반복 횟수가 1 2회 감소하였다(Kraft et al., 2010). 이외 체중의 $1.9 \%$ 탈수부터 하지 등척성 (isometric) 운동능력이 감소되고, $2.6 \%$ 탈수부터 등속 성(isokinetic) 운동능력도 감소되었다(Hayes \& Morse, 2010). 탈수는 인지능력에도 영향을 미칠 수 있 다. Wilson \& Morley(2003)는 탈수가 세포와 호르몬의 변화를 유발하여 인지 기능의 저하에도 영향을 미칠 수 있다고 제안하였다. 선행 연구들을 종합한 Grandjean \& Grandjean(2007)의 연구에서 체중의 $2 \%$ 탈수가 일어 났을 때 시각 운동 추적 테스트(visual-motor tracking), 단기 기억력 테스트, 집중력 테스트 그리고 연산 능력 테스트 측정결과가 유의하게 감소하는 것을 확 인하였다.

일반적으로 전해질 중 나트륨의 결핍은 잘 일어나지 않지만, 과도한 발한과 함께 체중의 약 $3 \%$ 이상 수분이 손실될 경우 나트륨 결핍이 관찰되었고, 체내 전해질이 부족할 경우 근육 경련, 구역질, 구토, 현기증, 마비가 일 어나고, 심각한 경우에는 혼수상태까지 이른다고 보고되 었다(Gropper \& Smith, 2013). 수분과 전해질의 불균 형 유발은 운동능력을 저하한다(Shirreffs \& Sawka, 2011).

이상 살펴본 바와 같이 탈수는 경기력 저하를 유발하 지만, 실제 선수들의 수분 섭취는 부족한 것을 확인하였 다. 해외에서는 다양한 선행 연구들을 바탕으로 표준화된 발한테스트를 현장에서 적용하여 객관적 데이터를 수집. 공유하고 수분손실 평가 방법으로 활용하고 있다. 그리고 이를 통해 종목별, 선수 개인별 수분 섭취 지침을 제공하 고 있다.

국내에서는 트라이애슬론 선수의 모의 경기에서 체중 을 통한 전신 발한율, 요비중 그리고 혈액을 통한 전해질, 대사 산물, 혈장 삼투 농도, 면역 및 염증 지표를 측정한 연구 사례가 있다. 하지만 연구대상 수가 부족하고 스포 츠 현장에서 사용하기에 적합하지 않은 침습적인 방법을 사용하였다(Lee et al., 2012). 이외 이와 관련한 스포츠 현장 연구 및 사례는 거의 없는 상황이며, 이로 인해 체계 화된 실험 방법의 보급이 미흡한 실정이다.

따라서 본 연구에서는 국제적으로 표준화된 발한테스 트를 실내(배드민턴) 및 실외(럭비) 종목 선수의 훈련 중 상황에 적용하여 운동 전 체수분 상태, 운동 중 발한량, 땀의 전해질 구성 및 수분섭취 상태를 평가하고 그 결과 를 확인함으로써, 국내 환경에서 운동선수의 체수분 상태 평가 및 수분섭취 지침 마련을 위한 객관적인 실험 방법 제시와 기초자료를 제공하고자 하였다. 


\section{연구방법}

\section{연구대상}

본 연구의 대상자는 G도에 위치한 K대학 소속 배드민 턴 선수, 럭비 선수 중 본 연구에 자발적으로 참여를 신청 한 남자선수 각 14 명과 17 명으로 구성하였다. 유질환자 와 측정변인에 영향을 주는 약물을 복용한 자(이뇨제 등) 는 제외하였다. 이 연구는 $K$ 대학교 생명윤리심의위원회 의 승인(KHGIRB-20-009)을 받은 후 진행되었으며, 연 구대상자들의 신체 특성은 〈Table 1)과 같다.

Table 1. Characteristic of subjects

$($ mean $\pm \mathrm{SD})$

\begin{tabular}{|c|c|c|c|c|}
\hline Variables & $\begin{array}{l}\text { Badminton } \\
\quad(n=14)\end{array}$ & $\begin{array}{l}\text { Rugby } \\
(\mathrm{n}=17)\end{array}$ & $\mathrm{t}$ & $\mathrm{p}$ \\
\hline $\begin{array}{c}\text { Age } \\
\text { (years) }\end{array}$ & $20.29 \pm 1.20$ & $20.23 \pm 0.90$ & .133 & .895 \\
\hline $\begin{array}{l}\text { Height } \\
\text { (cm) }\end{array}$ & $178.79 \pm 5.16$ & $180.59 \pm 7.11$ & -.792 & .435 \\
\hline $\begin{array}{l}\text { Weight } \\
\text { (kg) }\end{array}$ & $74.44 \pm 8.99$ & $95.15 \pm 18.07$ & -4.143 & .000 \\
\hline$\underset{\left(\mathrm{kg} / \mathrm{m}^{2}\right)}{\mathrm{BMI}}$ & $23.29 \pm 2.71$ & $29.07 \pm 4.79$ & -4.219 & .000 \\
\hline
\end{tabular}

\section{측정 항목 및 방법}

\section{1) 전신 발한량 및 전신 발한율}

전신 발한량(whole-body sweat loss)을 계산하기 위 해 운동 시작 전 체중을 $0.05 \mathrm{~kg}$ 단위로 기록하였다. 운동 중 섭취하는 물, 음료와 배설하는 소변, 대변의 양은 소저 울(CAS, SW-02, Korea)를 이용하여 $1 \mathrm{~g}$ 단위로 기록하 였다. 전신 발한량과 전신 발한율 (whole-body sweating rate)은 다음과 같은 공식으로 계산하였다.

- 전신 발한량 $(\mathrm{L})=$ 운동 전 체중 - (운동 후 체중 운동 중 수분 섭취 + 운동 중 소변, 대변)

- 전신 발한율 $(\mathrm{L} / \mathrm{h})=$ 전신 발한량 $\div$ 운동 시간

운동 중 수분 섭취량은 운동 전과 후 미리 측정된 개인 물병의 무게 차이 값으로 하였다. 운동 중 소변 및 대변 배설량은 운동 중 모든 배설물을 모으게 한 후 무게를 측
정하였다. 운동 후 땀이 피부에 맺혀있을 경우는 마른 수 건을 이용하여 땀을 닦게 하였다. 흘린 땀이 옷에 흡수되어 체중에 영향이 미치는 것을 최소화하기 위해 대상자 체중 측정 시, 양말과 신발은 탈의하고 속옷, 반팔, 반바지 정 도의 최소한의 옷만 입고 체중을 측정하였다(Baker, 2016).

\section{2) 요비중}

선수의 중간 소변을 수집하고 휴대용 디지털 요비중계 (Atago, PAL-10S, Japan)로 측정하여 운동 전 수분 상 태를 평가하고, 수치가 $\geq 1.023$ 이상일 경우 탈수로 판단 하였다(Cheuvront \& Sawka, 2005).

3) 땀 수집

땀의 수집은 파라필름으로 덮여있고 점착성이 높은 땀 흡수 패치 (sweat patch, 3MTM, Tegaderm +Pad 3586, USA)를 이용했으며, 부착 부위는 〈Fig. 1)과 같다 (Baker et al., 2009). 본 연구에서는 전완 후면의 중앙 부위에서 수집한 땀을 통해 전신 땀의 전해질 농도를 예 측했고(Baker, 2016), 추가적으로 가슴 상부와 허벅지 앞면의 중앙 부위에서 땀을 수집하여 결측값이 발생할 경 우 대체 샘플로 사용하였다.

땀의 수집 순서는 다음과 같았다. (1) 패치 부착 부위에 털이 많을 경우에는 면도를 진행한다. (2) 무기 이온을 제 거하기 위해 증류수 또는 탈이온수(deionized water)로 세척하고 알코올 솜으로 소독한다. (3) 전완 후면의 중앙, 이마, 가슴 상부, 등의 견갑골, 허벅지 앞면의 중앙에 패 치를 부착한다. (4) 운동 후, 패치 제거 시 실험용 장갑과 소독된 포셉(forceps)을 이용하여 오염을 방지한다. (5) 패치에 모인 땀이 흡수된 패드를 분리하여 일회용 주사기 에 넣는다. (6) 일회용 주사기로 땀이 흡수된 패드를 압축 하여 $10 \mathrm{ml}$ 큐벳에 짜낸다. 현장에서 땀의 전해질을 분석 하지 못하고 실험실로 이동해 분석할 경우 땀이 담긴 큐 벳을 파라필름으로 밀봉한 후 $4^{\circ} \mathrm{C}$ 이하에서 보관하며 최 대 3일 이내에 측정하도록 한다(Collie et al., 2014). 


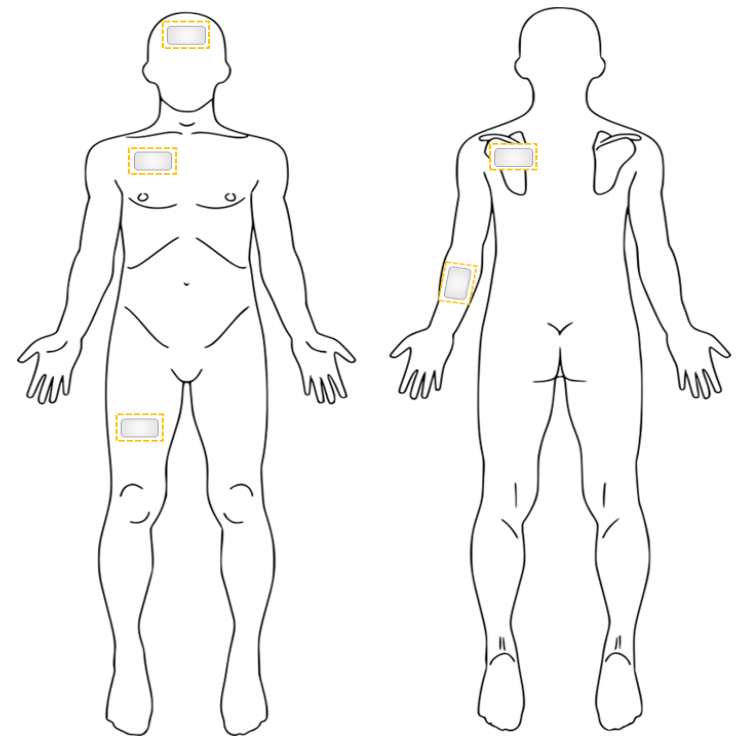

Fig. 1 Attachment position of the sweat patch

\section{4) 땀의 전해질 분석}

땀의 전해질은 휴대용 전해질 분석기(Horiba, LAQUAtwin Na-11 \& LAQUAtwin K-11, Japan)를 이용하여 분석하였다. 전완 후면의 중앙에서 수집한 땀을 활용하여 전신에서 땀 배출 시 손실되는 전해질량을 계산 할 경우 아래의 나트륨 \& 칼륨 손실량 방정식을 적용하 였다(Baker, 2016).

- 나트륨 손실량

(1) 전신 땀의 나트륨 농도 $(\mathrm{mmol} / \mathrm{L})=0.57 \times($ 전 완 땀의 나트륨 농도) +11.05 (2) 전신 땀의 나트 륨 손실량 $(\mathrm{mmol})=$ 전신 발한량 $(\mathrm{L}) \times$ 전신 땀의 나트륨 농도 $(\mathrm{mmol} / \mathrm{L})$ (3) 전신 땀의 나트륨 손실량 $(\mathrm{g})=$ 전신 땀의 나트륨 손실량 $(\mathrm{mmol}) \times$ $22.99 \mathrm{mg} / \mathrm{mmol} \times 1 \mathrm{~g} \div 1000 \mathrm{mg}$

> 칼륨 손실량

(1) 전신 땀의 칼륨 농도 $(\mathrm{mmol} / \mathrm{L})=0.51 \times($ 전완 땀의 칼륨 농도) +1.18 (2) 전신 땀의 칼륨 손실량 $(\mathrm{mmol})=$ 전신 발한량 $(\mathrm{L}) \times$ 전신 땀의 칼륨 농도 $(\mathrm{mmol} / \mathrm{L})$ (3) 전신 땀의 칼륨 손실량 $(\mathrm{g})=$ 전신 땀 의 칼륨 손실량 $(\mathrm{mmol}) \times 39.10 \mathrm{mg} / \mathrm{mmol} \times 1 \mathrm{~g} \div$ $1000 \mathrm{mg}$

\section{5) 기타 사항}

본 연구는 평소 진행하는 훈련 상황에서 기초자료를 수집하는 것을 최우선으로 하였기에 선수들에게 추가적 인 트레이닝, 투여 및 섭취 등의 처치는 실시하지 않았으 며, 단면 연구로 설계하여 진행하였다. 정확한 측정과 검 사를 위해 카페인과 알코올 섭취는 측정 1 일 전부터 제한 하였다. 이를 제외하고 식사와 수분 섭취는 평소처럼 하 도록 유도하였다. 음료는 선수별로 물 또는 스포츠 드링 크 등 선호하는 것을 선택할 수 있지만, 본 연구에서는 물 을 사용하였다.

두 집단의 훈련 환경은 〈Table 2〉에 제시된 바와 같다. 훈련 환경의 온도 및 습도는 디지털 온습도계(SATO, PC-5400TRH, Japan)로 측정하였다. 훈련 방법은 배드 민턴 집단의 경우 복식 경기 규정으로 모의 경기를 진행 하는 방식으로 훈련하였고, 럭비 집단의 경우 태클과 몸 싸움 없이 미니 게임 방식으로 훈련을 진행하였다. 훈련 시간은 각각 충분한 발한이 이루어진다고 판단되는 60 분 동안으로 진행하였다. 훈련 중 식별된 음료와 음식물은 자유롭게 섭취하도록 하였으며 흘리거나 버리지 않도록 주의시켰다. 훈련 중 선수들이 배설을 요청할 경우 사전 에 식별 표시하고 무게를 측정한 $1 \mathrm{~L}$ 통을 주어 수집하도 록 하였다.

Table 2. Environment condition of the test day

\begin{tabular}{ccc}
\hline \hline & Badminton & Rugby \\
\hline Temperature $\left({ }^{\circ} \mathrm{C}\right)$ & 22.4 & 32.7 \\
\hline Humitidy $(\%)$ & 58.9 & 42.8 \\
\hline Wind velocity $(\mathrm{m} / \mathrm{s})$ & 0.2 & 4.0 \\
\hline \hline
\end{tabular}

\section{통계 처리}

본 연구에서 획득한 자료는 SPSS version 23.0 for Window(SPSS Inc., Chicago, USA)를 이용하여 분석 했으며, 모든 결과는 평균(mean)과 표준편차(standard deviation; SD)로 제시하였다. 집단 간 신체 특성 차이 를 검증하기 위하여 독립표본 t-검정을 적용하였다. 통계 분석의 유의수준 $(\alpha)$ 은 0.05 로 설정하였다. 
Table 3. Measured results of each variables

$($ mean \pm SD $)$

\begin{tabular}{cccccc}
\hline \hline & USG $(\mathrm{kg} / \mathrm{L})$ & Body mass change $(\mathrm{kg})$ & Fluid intake $(\mathrm{L})$ & Excretion $(\mathrm{L})$ & Sweat rate $(\mathrm{L} / \mathrm{h})$ \\
\hline Badminton $(\mathrm{n}=14)$ & $1.024 \pm 0.004$ & $-0.381 \pm 0.210$ & $0.656 \pm 0.239$ & 0.000 & $1.037 \pm 0.315$ \\
\hline Rugby $(\mathrm{n}=17)$ & $1.024 \pm 0.004$ & $-0.547 \pm 0.547$ & $1.440 \pm 0.595$ & 0.000 & $1.987 \pm 0.386$ \\
\hline \hline
\end{tabular}

\section{연구결과}

\section{요비중, 체수분량 변화, 수분 섭취량 및 발한율}

배드민턴, 럭비 선수들의 훈련 전 요비중과 훈련 중 수 분 섭취, 그리고 훈련을 통한 발한율을 측정한 결과는 〈Table 3〉과 같다.

운동 전 요비중은 배드민턴 집단과 럭비 집단 모두 $1.024 \pm 0.004 \mathrm{~kg} / \mathrm{L}$ 로 나타났다. 운동 전·후 체중 변화는 배드민턴 집단 $-0.381 \pm 0.210 \mathrm{~kg}$, 럭비 집단 $-0.547 \pm$ $0.547 \mathrm{~kg}$ 으로 나타났다. 운동 중 수분 섭취량은 배드민턴 집단 $0.656 \pm 0.239 \mathrm{~L}$, 럭비 집단 $1.440 \pm 0.595 \mathrm{~L}$ 로 나타 났다. 그리고 운동 중 발한율은 배드민턴 집단 $1.037 \pm$ $0.315 \mathrm{~L} / \mathrm{h}$, 럭비 집단 $1.987 \pm 0.386 \mathrm{~L} / \mathrm{h}$ 로 나타났다.

\section{땀의 전해질 농도 및 손실량}

배드민턴, 럭비 선수들의 땀을 흡수 패치를 통해 수집 하고 전해질 분석기를 통해 분석한 땀의 나트륨·칼륨 농 도와 나트륨·칼륨 손실량은 〈Table 4〉와 같다.

Table 4. Electrolytes concentration and loss (mean \pm SD)

\begin{tabular}{ccc}
\hline \hline Variables & Badminton $(\mathrm{n}=14)$ & Rugby $(\mathrm{n}=17)$ \\
\hline $\mathrm{Na}^{+} \begin{array}{c}\text { concentration } \\
(\mathrm{mmol} / \mathrm{L})\end{array}$ & $53.6 \pm 20.2$ & $55.6 \pm 15.2$ \\
\hline $\mathrm{K}^{+} \begin{array}{c}\text { concentration } \\
(\mathrm{mmol} / \mathrm{L})\end{array}$ & $4.1 \pm 0.7$ & $4.3 \pm 0.5$ \\
\hline $\mathrm{Na}^{+}$loss $(\mathrm{g})$ & $1.02 \pm 0.48$ & $1.95 \pm 0.52$ \\
\hline $\mathrm{K}^{+}$loss $(\mathrm{g})$ & $0.08 \pm 0.02$ & $0.15 \pm 0.03$ \\
\hline \hline
\end{tabular}

운동 중 흘린 땀의 나트륨 농도는 배드민턴 집단 $53.6 \pm 20.2 \mathrm{mmol} / \mathrm{L}$, 럭비 집단 $55.6 \pm 15.2 \mathrm{mmol} / \mathrm{L}$ 으로 나타났고, 칼륨 농도는 배드민턴 집단 $4.1 \pm 0.7 \mathrm{mmol} / \mathrm{L}$, 럭비 집단 $4.3 \pm 0.5 \mathrm{mmol} / \mathrm{L}$ 으로 나타났다. 운동 중 전신
나트륨 손실량은 배드민턴 집단 $1.02 \pm 0.48 \mathrm{~g}$, 럭비 집단 $1.95 \pm 0.52 \mathrm{~g}$ 으로 나타났고, 전신 칼륨 손실량은 배드민턴 집단 $0.08 \pm 0.02 \mathrm{~g}$, 럭비 집단 $0.15 \pm 0.03 \mathrm{~g}$ 으로 나타났다.

\section{논 의}

\section{요비중, 체수분량 변화, 수분 섭취량 및 발한율}

요비중은 탈수와 수분 보충에 의한 수분 상태 변화를 정확히 반영하기는 어렵다는 보고도 있지만(Popowski et al., 2001), 요비중은 비침습적이고 빠르며 간단하게 체수분 상태를 판단할 수 있기 때문에 많은 스포츠 현장 에서 체수분 상태평가에 적용하고 있다(Arnaoutis et al., 2015; McDermott et al., 2017; Osterberg et al., 2009). 본 연구의 요비중 결과를 통해 배드민턴 집단과 럭비 집단 모두 운동 전 수분 섭취가 충분치 않다는 것을 확인하였다. 요비중이 $\geq 1.023 \mathrm{~kg} / \mathrm{L}$ 로 나타난 배드민턴 선수는 전체의 $79 \%$ 였고, 럭비 선수는 전체의 $53 \%$ 였다. 각 집단의 절반 이상이 정상 범위보다 낮은 수분 상태로 나타났기 때문에 하루 동안, 운동 전 수분 섭취 지침이 필 요하다. IOM(Institute of Medicine)에서 제안한 하루 수분 섭취 권장량은 남성 $3.7 \mathrm{~L}$, 여성 $2.7 \mathrm{~L}$ 이다. 하지만 격렬한 운동과 열 스트레스 상황에 있을 경우 하루 수분 필요량은 증가하므로, 선수들은 하루 권장량 이외에 추가 적으로 더 많은 수분을 섭취해야 한다(Sawka et al., 2005). ACSM에서는 최소 운동 4시간 전 체중 $1 \mathrm{~kg}$ 당 5 7ml를 천천히 섭취하도록 제안하였고, 섭취하더라도 요비중이 높거나 소변 색상이 진할 경우에는 운동 2시간 전에 체중 $1 \mathrm{~kg}$ 당 3 5ml를 천천히 섭취하도록 제안하고 있다(Sawka et al., 2007). 지구성 종목 운동선수들의 경우, 운동 2 시간 전 체중 $1 \mathrm{~kg}$ 당 $5 \sim 10 \mathrm{ml}$ 의 음료를 천천 히 섭취하게끔 제안한다(Goulet, 2013). 
전신 발한량 측정에서 $1 \mathrm{~g}$ 의 체중 변화는 $1 \mathrm{ml}$ 수분 변 화와 동등하다고 추정한다(Shirreffs, 2000, Shirreffs, 2003). 운동 중 대사로 인한 기질 산화가 체중에 미치는 영향은 미미하다(Maughan et al., 2007). 그러므로 훈 련 시간 동안 수분 이외 요소가 체중에 영향을 주지 않을 것으로 판단한다(Shirreffs, 2003). 체내 총수분(TBW; total body water) 평가는 물의 동위원소 중 산화중수소 $\left(\mathrm{D}_{2} \mathrm{O}\right.$ 또는 $\left.2 \mathrm{H}_{2} \mathrm{O}\right)$ 를 이용한 최적의 방법이 있으나, 훈련 이나 시합 현장에서 활용하기에는 불가능하므로 체중 변 화 측정이 가장 현실적인 방법이다(Cheuvront \& Sawka, 2005). 운동 전·후 두 집단의 체수분량 변화는 체중의 $2 \%$ 이내의 손실로 운동 수행능력의 유의한 감소 가 나타나지 않는 수준이었다. 운동 중 수분 섭취량은 두 집단 모두 시간당 400 800ml 정도를 수시로 섭취하도 록 하는 $\mathrm{ACSM}$ 의 권장에 부합했다(Sawka et al., 2007). 하지만 운동 시간의 길어짐, 운동 강도의 상승, 온도와 습도의 상승 그리고 특정 종목 특성 등을 고려하 여 수분 섭취량 설정은 달라질 수 있다. 운동 후 수분 섭 취 권장량은 운동 중 체중 감소량의 $150 \%$ 이상에 해당하 는 양을 섭취하도록 제안하며 (Sawka et al., 2007), 본 연구결과를 적용했을 때 권장 수분 섭취량은 배드민턴 집단 $0.572 \sim 0.762 \mathrm{~L}$, 럭비 집단 $0.821 \sim 1.094 \mathrm{~L}$ 정도이다.

운동 중 발한율을 측정한 선행 연구들을 종합한 Barnes et al.(2019)에 의하면 운동선수 1,303명의 평 균 발한율은 $1.13 \pm 0.58 \mathrm{~L} / \mathrm{h}$ 로 나타났으며, 이 중 팀 및 기술 종목 운동선수 1,022 명의 발한율은 $1.10 \pm 0.58 \mathrm{~L} / \mathrm{h}$ 였다(평균 온도 $25.0 \pm 4.6^{\circ} \mathrm{C}$, 평균 습도 $54 \pm 18 \%$ ). 온도 $28.6 \pm 1.9^{\circ} \mathrm{C}$, 습도 $65 \pm 5 \%$ 환경에서 럭비선수 10 명을 측 정한 Godek et al.(2005)의 연구에서는 발한율이 $2.15 \pm 0.56 \mathrm{~L} / \mathrm{h}$ 였다. 발한율은 개인별, 환경 조건(온도, 습도), 체력 수준, 운동 강도, 운동 시간, 장비 착용 상태 그리고 열 순응 정도에 따라 달라질 수 있으며(Sawka \& Montain, 2000), 체내 열 축적에 영향을 주는 체표면적 과 체지방률에 영향을 받는 것으로 알려졌다(Havenith \& Middendorp, 1990). 그러므로 본 연구의 대상자 신 체 특성 차이는 운동 중 발한율에 영향을 미칠 것으로 예 상할 수 있다. 하지만 선행 연구들을 종합한 Barnes et al.(2019)의 연구에서 1,303명의 발한율은 성별, 운동 강도 그리고 종목에 영향을 받았지만, 연령대, 훈련 환경,
운동 경력 그리고 계절에는 유의한 영향을 받지 않았다. 이를 통해 성별, 운동 강도 그리고 종목이 유사하고 큰 차 이가 없는 환경 조건에서 측정한 발한율 결과라면 수분섭 취 전략의 기초자료로 활용하여도 가능하다고 사료된다. 본 연구 주제와 관련된 후속 연구들에서는 발한율 및 땀 의 전해질 농도에 영향을 미칠 수 있는 요소를 추가로 측 정하는 것을 제안하며, 이를 통해 수집되는 기초자료를 종합하여 분석하는 것이 필요하다고 사료된다.

\section{땀의 전해질 농도 및 손실량}

발한테스트에서 땀의 전해질 분석은 전신 전해질 손실 량을 파악하기 위해 필수적으로 측정해야 하는 항목이다. 현재까지는 Shirreffs \& Maughan(1997)이 실시한 전신 땀 수집(WBW; whole body wash-down) 방법이 전신 땀 의 전해질을 수집하는데 가장 최적의 방법으로 알려져 있 다. 그러나 이 방법은 스포츠 현장에 적용하기 어렵다. Baker et al.(2009)은 전신 땀 수집 방법으로 수집한 땀 과 다섯 부위 땀 흡수 패치 부착 방법으로 수집한 땀의 전 해질 농도가 높은 상관관계 $\left(\mathrm{Na}^{+} \mathrm{r}=0.97, \mathrm{~K}^{+} \mathrm{r}=0.72\right)$ 를 갖는 것으로 확인했다. 특히 전완 후면의 중앙 부위에 패치 를 붙여 수집한 땀은 나머지 부위보다 상관관계 $\left(\mathrm{Na}^{+}\right.$ $\mathrm{r}=0.96, \mathrm{~K}^{+} \mathrm{r}=0.77$ )가 더 높게 나타났다(Baker, 2016). 이를 바탕으로 스포츠 현장에서 발한테스트를 진행하는 연 구에서는 대부분 전완 후면의 중앙에서 수집한 땀으로 전신 땀의 농도를 예측한다(Barnes et al., 2019; Ranchordas et al., 2017, Godek et al., 2010; Maughan et al., 2005).

스포츠 현장에서 땀의 전해질 농도 측정은 주로 휴대 용 전해질 분석기를 이용한다. Baker et al.(2014)은 HPLC(high performance liquid chromatography)를 통해 땀의 전해질 농도를 분석한 결과와 휴대용 전해질 분석기를 통한 결과가 높은 상관관계 $\left(\mathrm{Na}^{+} \mathrm{r}=0.96, \mathrm{~K}^{+}\right.$ $\mathrm{r}=0.88)$ 를 나타내는 것을 확인하였다.

Baker et al.(2009)이 실험실에서 운동선수 20명을 대상으로 발한테스트를 진행한 연구의 경우 다섯 부위에 땀 흡수 패치를 부착하는 방법으로 측정하였을 시 땀의 나트륨 농도는 평균 $59.0 \pm 27.0 \mathrm{mmol} / \mathrm{L}$ 그리고 전완에 땀 흡수 패치를 부착하는 방법으로 측정하였을 시 땀의 
나트륨 농도는 평균 $52.0 \pm 32.0 \mathrm{mmol} / \mathrm{L}$ 였다. 그리고 두 방법의 나트륨 농도는 유의한 차이가 없었다. Godek et al. (2010)이 풋볼 선수를 대상으로 훈련 시 전완에 땀 흡 수 패치를 부착하여 발한테스트를 진행한 연구에서 back 과 receiver 포지션 선수 18 명의 나트륨 농도는 평균 $50.0 \pm 16.0 \mathrm{mmol} / \mathrm{L}$, Linebackers과 Quarterbacks 포지 션 선수 12 명의 나트륨 농도는 평균 $48.2 \pm 23.0 \mathrm{mmol} / \mathrm{L}$ 그리고 Linemen 포지션 선수 14명의 나트륨 농도는 평 균 $52.8 \pm 25.0 \mathrm{mmol} / \mathrm{L}$ 였다. 그리고 포지션별로 땀의 나 트륨 농도는 유의한 차이가 없었다. 선행 연구들을 종합 한 Baker et al.(2016)에 의하면, 운동선수 506명의 땀 의 나트륨 농도는 연령대, 계절에 따라 유의한 차이가 있 었지만, 성별, 종목 간, 실험실과 스포츠 현장 간에는 유 의한 차이가 없었다. 이를 통해 비슷한 연령대와 비슷한 계절 조건에서 측정한 나트륨 농도 결과라면 나트륨 보충 을 위한 수분섭취 전략의 기초자료로 활용하여도 가능하 다고 사료된다.

일반적인 땀의 칼륨 농도 범위는 2 $10 \mathrm{mmol} / \mathrm{L}$ 로 보 고되었으며, 발한 속도가 상승하면 땀의 나트륨과 염소의 경우 발한 속도에 비례해서 배출량이 상승하지만, 땀의 칼륨의 경우 발한 속도가 상승하더라도 큰 영향을 받지 않는 것으로 알려져 있다(Baker, 2017). 만일 땀의 칼륨 농도가 비정상적으로 높다면 땀을 수집한 샘플이 오염, 증발 그리고 침출되었을 가능성이 있다(Weschler, 2008). 따라서 땀의 칼륨 농도 측정의 주된 목적은 땀을 수집한 샘플의 이상 유무를 파악하기 위함이다.

대부분 운동선수들의 땀 나트륨 농도는 $50 \mathrm{mmol} / \mathrm{L}$ 미 만으로 4 5시간 동안 지속적으로 운동하여 땀을 흘릴 경 우 4.60 5.75g/L가 손실될 수 있다. 이 정도 양은 $70 \mathrm{~kg}$ 인 사람이 보유한 총 나트륨 양 $(2500 \mathrm{mmol}$ 또는 $58 \mathrm{~g})$ 의 약 $10 \%$ 에 해당되며, 전신 나트륨 손실량은 3 $4 \mathrm{~g}$ 을 넘 지 않도록 유의해야 한다(Coyle, 2004). 본 연구의 발한 테스트 결과를 통해 훈련 및 시합으로 전신 나트륨 손실 량이 $3 \mathrm{~g}$ 이상 도달하는 시간을 예상해본다면 배드민턴 집단은 2 시간 56 분, 럭비 집단은 1 시간 32 분이 걸린다. 즉 훈련 및 시합을 2 시간 이상 진행할 경우 전신 나트륨 손실량은 3 4g이 될 가능성이 높다. 따라서 이런 상황에 서는 나트륨이 포함된 음료의 섭취가 권장된다(Coyle, 2004, Shirreffs, 2009). 발한을 통한 칼륨 손실이 어떠
한 문제를 야기하는지는 정확하게 보고된 바 없지만, 음 료를 통해 칼륨을 추가 섭취하는 것은 수분 보충 효율에 영향을 줄 수 있다고 제안하였다(Shirreffs, 2003). 전해 질은 손실된 양 만큼 보충해주는 것을 가장 이상적으로 보며, 이를 보충할 수 있는 음료의 사용이 권장된다 (Shirreffs, 2003).

발한테스트 결과를 기반으로 수분 섭취 전략을 제공하 는 것이 논리적으로 타당하지만, 실험 방법 보급의 미흡 및 전문 인력 부족 등의 현실적인 어려움으로 인해 널리 적용되지 못하고 있다(Sawka et al., 2007). 하지만 최 근 많은 국가와 연구소에서는 스포츠 현장에 특화된 체수 분 상태평가와 발한테스트를 적용하여 다양한 탈수 상황 에 놓인 선수들을 위한 과학적인 수분 섭취 지침을 마련 하고, 사전에 선수 개개인의 발한율 및 전신 전해질 손실 량을 파악하여 경기 중에 사용할 수 있는 수분 섭취 데이 터를 제공하고 있다.

\section{결론 및 제언}

본 연구는 스포츠 현장에서 체수분 상태평가와 발한테 스트를 진행한 선행 연구의 실험 방법을 확인하고 실내 (배드민턴) 및 실외(럭비) 종목에 현장 적용하여 그 결과 를 평가하였다. 훈련 전 대상 선수의 절반 이상이 정상 범 위보다 낮은 체수분 상태를 나타냈고, 운동 중·후에 필요 한 수분과 전해질 섭취량을 확인하였다. 이를 통해 상세 하고 효율적인 체수분 관리 지침이 요구된다고 판단된다.

다양한 운동 상황과 환경에서 많은 데이터를 축적하기 위해서는 체수분 상태평가와 발한테스트가 반드시 필요 하며, 표준화된 측정방법을 사용한다면 더 높은 객관성도 담보할 수 있으리라 본다. 이를 통해 수집되는 기초자료 를 기반으로 선수들에게 종목별, 상황별 체수분 관리 지 침과 개별적 전략을 제공할 수 있게 되기를 기대한다.

\section{참고문헌}

Armstrong, L. E., Costill, D. L., \& Fink, W. J. (1985). Influence of diuretic-induced dehydration on competitive running 
performance. Medicine and Science in Sports and Exercise, 17(4), 456-461.

Arnaoutis, G., Kavouras, S. A., Angelopoulou, A., Skoulariki, C., Bismpikou, S., Mourtakos, S., \& Sidossis, L. S. (2015). Fluid balance during training in elite young athletes of different sports. Journal of Strength and Conditioning Research, 29(12), 3447-3452.

Baker, L. B. (2016). Sweat testing methodology in the field: challenges and best practices. Sports Science Exchange, 28(161), 1-6.

Baker, L. B. (2017). Sweating Rate and Sweat Sodium Concentration in Athletes: A Review of Methodology and Intra/Interindividual Variability. Sports Medicine, 47(1), 111-128.

Baker, L. B., Barnes, K. A., Anderson, M. L., Passe, D. H., \& Stofan, J. R. (2016). Normative data for regional sweat sodium concentration and whole-body sweating rate in athletes. Journal of Sports Sciences, 34(4), 358-368.

Baker, L. B., Stofan, J. R., Hamilton, A. A., \& Horswill, C. A. (2009). Comparison of regional patch collection vs. whole body washdown for measuring sweat sodium and potassium loss during exercise. Journal of Applied Physiology, 107(3), 887-895.

Baker, L. B., Ungaro, C. T., Barnes, K. A., Nuccio, R. P., Reimel, A. J., \& Stofan, J. R. (2014). Validity and reliability of a field technique for sweat $\mathrm{Na}+$ and $\mathrm{K}+$ analysis during exercise in a hot-humid environment. Physiological Reports, 2(5), e12007.

Barnes, K. A., Anderson, M. L., Stofan, J. R., Dalrymple, K. J., Reimel, A. J., Roberts, T. J., Randell, R. K., Ungaro, C. T., \& Baker, L. B. (2019). Normative data for sweating rate, sweat sodium concentration, and sweat sodium loss in athletes: An update and analysis by sport. Journal of Sports Sciences, 37(20), 2356-2366.

Bradley, A. W., Greig, W., Jeremiah, J. P., Chris, R. A., Rodney, S., \& Paul, B. L. (2015). Current hydration guidelines are erroneous: dehydration does not impair exercise performance in the heat. British journal of sports medicine, 49(16), 1077-1083.

Cheuvront, S. N., \& Sawka, M. N. (2005). Hydration assessment of athletes. Sports Science Exchange, 18(2), 1-12.

Collie, J. T., Massie, R. J., Jones, O. A., LeGrys, V. A., \& Greaves, R. F. (2014). Sixty-five years since the New York heat wave: advances in sweat testing for cystic fibrosis. Pediatric
Pulmonology, 49(2), 106-117.

Coyle, E. F. (2004). Fluid and fuel intake during exercise. Journal of Sports Sciences, 22(1), 39-55.

Godek, S. F., Bartolozzi, A. R., \& Godek, J. J. (2005). Sweat rate and fluid turnover in American football players compared with runners in a hot and humid environment. British Journal of Sports Medicine, 39(4), 205-211.

Godek, S. F., Peduzzi, C., Burkholder, R., Condon, S., Dorshimer, G., \& Bartolozzi, A. R. (2010). Sweat Rates, Sweat Sodium Concentrations, and Sodium Losses in 3 Groups of Professional Football Players. Journal of Athletic Training, 45(4), 364-371.

Goulet, E. D. B. (2013). Effect of exercise-induced dehydration on endurance performance: evaluating the impact of exercise protocols on outcomes using a meta-analytic procedure. British Journal of Sports Medicine, 47(11), 661-662.

Grandjean, A. C., \& Grandjean, N. R. (2007). Dehydration and Cognitive Performance. Journal of the American College of Nutrition, 26(5), 549S-554S.

Gropper, S. S., \& Smith, J. L. (2013). Advanced Nutrition and Human Metabolism(6th International ed.). $\mathrm{OH}$ : Cengage Learning.

Havenith, G., \& Middendorp, H. (1990). The relative influence of physical fitness, acclimatization state, anthropometric measures and gender on individual reactions to heat stress. European Journal of Applied Physiology and Occupational Physiology, 61(5-6), 419-427.

Haycock, G. B., Schwartz, G. J., \& Wisotsky, D. H. (1978). Geometric method for measuring body surface area: A height weight formula validated in infants, children and adults. The Journal of Pediatrics, 93(1), 62-66.

Hayes, L. D., \& Morse, C. I. (2010). The effects of progressive dehydration on strength and power: is there a dose response?. European Journal of Applied Physiology, 108(4), 701-707.

Kilding, A. E., Tunstall, H., Wraith, E., Good, M., Gammon, C., \& Smith, C. (2009). Sweat Rate and Sweat Electrolyte Composition in International Female Soccer Players during Game Specific Training. International Journal of Sports Medicine, 30(6), 443-447.

Kraft, J. A., Green, J. M., Bishop, P. A., Richardson, M. T., Neggers, Y. H., \& Leeper, J. D. (2010). Impact of dehydration on a full body resistance exercise protocol. European Journal of Applied Physiology, 109(2), 259-267. 
Kraft, J. A., Green, J. M., Bishop, P. A., Richardson, M. T., Neggers, Y. H., \& Leeper, J. D. (2012). The influence of hydration on anaerobic performance: a review. Research Quarterly for Exercise and Sport, 83(2), 282-292.

Lee, H. J., Kim, B. J., \& Lee, D. T. (2012). Fluid Intake, Body Water Balance, and Inflammatory Responses during Simulated Olympic Distance Triathlon in Elite Triathletes. Korean Journal of Sport Science, 23(2), 422-430.

Logan-Sprenger, H. M., Heigenhauser, G. J. F., Jones, G. L., \& Spriet, L. L. (2015). The effect of dehydration on muscle metabolism and time trial performance during prolonged cycling in males. Physiological Reports, 3(8), e12483.

Maughan, R. J., Shirreffs, S. M., \& Leiper, J. B. (2007). Errors in the estimation of hydration status from changes in body mass. Journal of Sports Sciences, 25(7), 797-804.

Maughan, R. J., Shirreffs, S. M., Merson, S. J., \& Horswill, C. A. (2005). Fluid and electrolyte balance in elite male football (soccer) players training in a cool environment, Journal of Sports Sciences, 23(1), 73-79.

McDermott, B. P., Anderson, S. A., Armstrong, L. E., Casa, D. J., Cheuvront, S. N., Cooper, L., Kenney, L., O'Connor, F. G., \& Roberts, W. O. (2017). National athletic trainers' association position statement: fluid replacement for the physically active. Journal of Athletic Training, 52(9), 877-895.

Osterberg, K. L., Horswill, C. A., \& Baker, L. B. (2009). Pregame urine specific gravity and fluid intake by National Basketball Association players during competition. Journal of Athletic Training, 44(1), 53-57.

Popowski, L. A., Oppliger, R. A., Patrick, L. G., Johnson, R. F., Kim, J. A., \& Gisolf, C. V. (2001). Blood and urinary measures of hydration status during progressive acute dehydration. Medicine and Science in Sports and Exercise, 33(5), 747-753.

Ranchordas, M. K., Tiller, N. B., Ramchandani, G., Jutley, R., Blow, A., Tye, J., \& Drury, B. (2017). Normative data on regional sweat-sodium concentrations of professional male team-sport athletes. Journal of the International Society of Sports Nutrition, 14(40), DOI 10.1186/s12970-017-0197-4.

Sawka, M. N., \& Montain, S. J. (2000). Fluid and electrolyte supplementation for exercise heat stress. The American
Journal of Clinical Nutrition, 72(2), 564S-572S.

Sawka, M. N., Burke, L. M., Eichner, E. R., Maughan, R. J., Montain, S. J., \& Stachenfeld, N. S. (2007). Exercise and fluid replacement. Medicine and Science in Sports and Exercise, 39(2), 377-390.

Sawka, M. N., Burke, L. M., Eichner. E. R., Maughan, R. J., Montain, S. J., \& Stachenfeld, N. S. (2007). Exercise and Fluid Replacement. American College of Sports Medicine, DOI: 10.1249/mss.0b013e31802ca597.

Sawka, M. N., Cheuvront, S. N., \& Carter, R. (2005). Human water needs. Nutrition Reviews, 63(1), S30-S39.

Schoffstall, J. E., Branch, J. D., Leutholtz, B. C., \& Swain, D. E. (2001). Effects of dehydration and rehydration on the one-repetition maximum bench press of weight-trained males. Journal of Strength and Conditioning Research, 15(1), 102-108.

Shirreffs, S. M. (2000). Markers of hydration status. Journal of Sports Medicine and Physical Fitness, 40(1), 80-84.

Shirreffs, S. M. (2003). Markers of hydration status. European Journal of Clinical Nutrition, 57(2), S6-S9.

Shirreffs, S. M. (2003). The Optimal Sports Drink. Swiss Sports \& Exercise Medicine, 41(1), 25-29.

Shirreffs, S. M. (2009). Hydration in sport and exercise: water, sports drinks and other drinks. Nutrition Bulletin, 34(4), 374-379.

Shirreffs, S. M., \& Maughan, R. J. (1997). Whole body sweat collection in humans: an improved method with preliminary data on electrolyte content. Journal of Applied Physiology, 82(1), 336-341.

Shirreffs, S. M., \& Sawka, M. N. (2011). Fluid and electrolyte needs for training, competition, and recovery. Journal of Sports Sciences, 29(S1), S39-S46.

Weschler, L. B. (2008). Sweat electrolyte concentrations obtained from within occlusive coverings are falsely high because sweat itself leaches skin electrolytes. Journal of Applied Physiology, 105(4), 1376-1377.

Wilson, M-M. G., \& Morley, J. E. (2003). Impaired cognitive function and mental performance in mild dehydration. European Journal of Clinical Nutrition, 57(2), S24-S29. 


\section{훈련 시 현장 발한테스트를 통한 운동선수의 체수분 상태, 발한율, 땀의 전해질 농도 및 손실량 평가

\author{
배수진 ${ }^{1}$, 박현 ${ }^{2}$ \\ 1경희대학교 운동영양생화학실험실 대학원생 \\ 2경희대학교 운동영양생화학실험실 교수
}

〔목적〕 스포츠 현장에서 체수분 상태평가와 발한테스트를 진행한 선행 연구의 실험 방법을 확인하고 실제 국내 실내(배드민턴) 및 실외(럭비) 종목 선수에게 적용하여 운동 전 체수분 상태, 운동 중 발한량, 땀의 전해 질 구성을 분석과 수분 섭취 상태를 평가하는 것이다. 〔방법) 배드민턴 남자선수 14 명, 럭비 남자선수 17 명을 대상으로 평소 훈련하는 방법과 환경에서 한 시간 동안 측정을 진행하였다. 요비중으로 운동 전 체수분 상태를 평가하고, 발한테스트를 통해 운동 중 수분 손실과 땀의 전해질 농도 및 손실량을 조사하였다. 〔결과〕 운동 전 요비중은 배드민턴 집단과 럭비 집단 모두 $1.024 \pm 0.004 \mathrm{~kg} / \mathrm{L}$ 로 나타나 탈수상태인 것을 확인하였다. 운 동 중 발한율과 전신 전해질 손실량을 측정하여 필요한 수분 섭취량과 전해질 공급량을 확인하였다. (결론〕 본 연구는 선수의 탈수증상 예방과 경기력 유지를 위한 체수분 상태평가와 발한테스트를 국내 스포츠 현장에 적용하고 후속 연구에 필요한 실험 방법 제시와 기초자료를 제공하여 과학적인 체수분 관리 지침의 제작이 가능하도록 하는 데 의미가 크다고 사료된다.

주요어: 체수분 상태평가, 발한테스트, 요비중, 발한율, 땀의 나트륨·칼륨 농도, 나트륨·칼륨 손실량, 탈수 